\begin{abstract}
Ambrosio Fornet
Ensayista, crítico literario, escritor y guionista de cine, publicó su primera obra de creación en 1958 (A un paso del diluvio, cuentos). Se inició en la crítica literaria con el volumen de reseñas titulado En tres $y$ dos (1964) y con el ensayo En blanco y negro (1967), sobre la cuentística cubana hasta 1959. Entre sus principales obras sobresalen la Antología del cuento cubano contemporáneo (1967), la recopilación Cuentos de la Revolución Cubana (1971), y Alea: una retrospectiva crítica (1987). Ha publicado también El libro en Cuba (1994), un minucioso estudio sobre la imprenta en la época colonial que abre nuevas perspectivas para una sociología de la literatura cubana en este siglo.
\end{abstract}

\section{1}

Compárese, además, con el del Manifiesto comunista (1848), donde se describe la nueva dinámica que introduce la burguesía en todos los aspectos de la vida material y espiritual.
En la encrucijada del fin de siglo AMBROSIO FORNET

\title{
EN LA ENCRUCIJADA DEL FIN DE SIGLO
}

\author{
AMBROSIO FORNET
}

\section{1}

Permítanme comenzar con algunas precisiones. El tema que tengo asignado es el de la literatura y el pensamiento cubanos de finales del siglo diecinueve. Esto me plantea ciertos problemas metodológicos, relacionados con la posible periodización de esa compleja etapa. Recuerden que Cuba fue colonia española hasta 1898, destino que en América compartió con Puerto Rico. Las autoridades colonialistas solían llamar a Cuba «la siempre fiel» pero lo cierto es que la Isla era bastante díscola. En un lapso de veintisiete años, entre 1868 y 1895 , los cubanos desataron tres guerras por la independencia, la primera de las cuales duró diez años. Todo el pensamiento cubano y una buena parte de su producción simbólica estuvieron determinados desde entonces, directa o indirectamente, por las posiciones políticas que se asumían con respecto al status colonial: de un lado, los separatistas (unos aspirando a la total independencia, otros, a la anexión a los Estados Unidos), y del otro, los autonomistas, que abogaban por permanecer unidos a España, pero bajo un régimen de libertades cuyo modelo era el tipo de self-government imperante en Canadá (lo que por cierto lograron en enero de 1898 , cuando ya era demasiado tarde). En los Materiales de Consulta que les hemos entregado encontrarán ustedes un resumen de esas posiciones bajo el título de «Saco o Martí: evolución o revolución». Tal vez la historia íntegra del pensamiento cubano en el siglo diecinueve pueda resumirse en esos dos nombres y esas dos alternativas. $\mathrm{Pe}$ ro no debe olvidarse que en este drama co- lectivo hay un convidado de piedra: el esclavo. Todo lo que se dice o hace en la Cuba colonial tiene que ver con la posición que se asume, primero, ante la esclavitud, y después de su abolición, en 1886, ante el papel que las masas de ex-esclavos y de ciudadanos negros y mestizos podían desempeñar en la vida pública. Es lo que he llamado en otra parte, refiriéndome a José Antonio Saco, la pesadilla de los censos, el horror de los datos demográficos.

Contra ese telón de fondo podríamos hacer un primer intento de periodización. Desde una perspectiva estrictamente histórica -o política, si lo prefieren-, el fin de siglo cubano abarcaría un período de diecisiete años, el que va desde 1878 , en que termina la primera guerra, hasta 1895 , en que comienza la tercera. Entre ambas fechas habría un momento clave, 1887 , en que se decreta la llamada libertad de imprenta, tanto para Cuba como para Puerto Rico. Ahora bien, desde una perspectiva estrictamente literaria, el lapso podría reducirse a once años e iniciarse en 1882. En este instante crucial para la literatura cubana -e hispanoamericana, inclusiveaparecen Cecilia Valdés, de Cirilo Villaverde - la gran novela cubana del siglo- y el poemario Ismaelillo, de José Martí, que para muchos es el texto fundacional del Modernismo. A ellos habría que añadir un prólogo que Martí escribe ese mismo año y que se considera casi unánimemente el primer manifiesto del naciente movimiento literario' ${ }^{1}$. Si hiciéramos culminar el período, como ya dije, once años después -es decir, en 1893, fecha en que aparecen Leonela, de Nicolás Heredia, la última novela significativa del siglo, y Bustos y 
rimas, de Julián del Casal - estaríamos abarcando en ese lapso un impresionante corpus que, en diferentes géneros, incluiría tres novelas insólitas en el contexto de nuestra narrativa: Amistad funesta (1885), de Martí - la extraña irrupción del esteticismo en la literatura hispanoamericana-, Mi tio el empleado (1887), de Ramón Meza —una sátira política que, con Cecilia Valdés, forma el dúo de las grandes novelas cubanas del siglo-y la sátira filosófica Aventuras de las hormigas (1888), de Esteban Borrero Echeverría. Otras referencias obligadas del período serían $L a$ Edad de Oro (1889), revista para niños redactada íntegramente por Martí, sus Versos sencillos (1891), casi toda la obra literaria y periodística de Casal, la novela Sofía (1891), de Martín Morúa Delgado, y por último, aunque no en orden de importancia, las primeras muestras de la literatura de campaña que circularon libremente en la Isla, así como gran parte de la obra de los más notables ensayistas y críticos del siglo. No es poco decir. Superponiendo ambos esquemas cronológicos y extendiéndolos hasta el fin de la dominación española, tendríamos una parábola histórica y literaria sumamente representativa, ese lapso de dos décadas (1878-1898) que marca el fin de dos guerras y que nos permitiría incluir entre los textos otras muestras de la literatura de campaña, incluyendo su máximo exponente, el último Diario de Martí. La existencia de textos de esta naturaleza, por cierto — «la historia narrada por sus creadores», como la llamó Max Henríquez Ureña, de hecho una literatura otra, casi siempre excluída del canon- plantea problemas de otra índole a la hora de las clasificaciones y periodizaciones. Al igual que una parte del corpus al que hemos venido refiriéndonos, esa producción testimonial no siempre operaba en el ámbito cultural de la Isla - y por tanto no siempre incidía sobre su dinámica interna-, dado que se escribía o publicaba en las zonas rurales, por los combatientes, o en el extranjero, por los emigrados y exiliados. Hasta ahora estas bifurcaciones han sido una constante en la historia de nuestra literatura, aunque el signo ideológico de los textos respectivos, como es natural, difieran según las circunstancias.

Una última reflexión sobre el carácter de nuestra empresas: ¿Es posible hablar de pen- samiento y literatura como categorías distintas y excluyentes? ¿O es que estamos pensando en bellas letras, por un lado, y por el otro en ese tipo de prosa expositiva y reflexiva que se expresa a través de géneros como el ensayo y la crítica? Ya las inquisiciones de Gaos y sus discípulos pusieron de manifiesto que en nuestra América, más que filósofos propiamente dichos, había pensadores, cuyas reflexiones, por cierto, tendían a girar obsesivamente en torno a temas como el de la Identidad, tanto nacional como cultural. Pero habría que añadir que desde los Comentarios Reales, del Inca Garcilaso, hasta el Canto general, de Neruda y El siglo de las luces, de Carpentier, el pensamiento americano no siempre fluye por los cauces tradicionales del artículo y el ensayo. En nuestro caso bastaría pensar en Martí y Casal para ver cuánto hay de "poético» o «artístico» en sus textos narrativos y expositivos, y cuánto de reflexividad en sus versos. Esa compleja red de influencias recíprocas, ese fluido sistema de vasos comunicantes nos impide caer en la tentación de los deslindes categóricos. Algo semejante nos ocurre con la definición del Modernismo, asunto tan polémico como manoseado, pero que no vamos a soslayar. Si pudiéramos tapar el sol con un dedo, haciendo caso omiso de Martí y de Casal, nuestra tarea sería mucho más sencilla, pero también mucho menos estimulante.

\section{2}

Federico de Onís precisó en su momento que el Modernismo no era un movimiento literario sino el espíritu de una época de crisis, y que no tenía sentido disociarlo categóricamente de la modernidad puesto que ésta era, justamente, su aspiración suprema. Alfredo Roggiano, por su parte, lo calificó como
En la encrucijada del fin de siglo AMBROSIO FORNET 


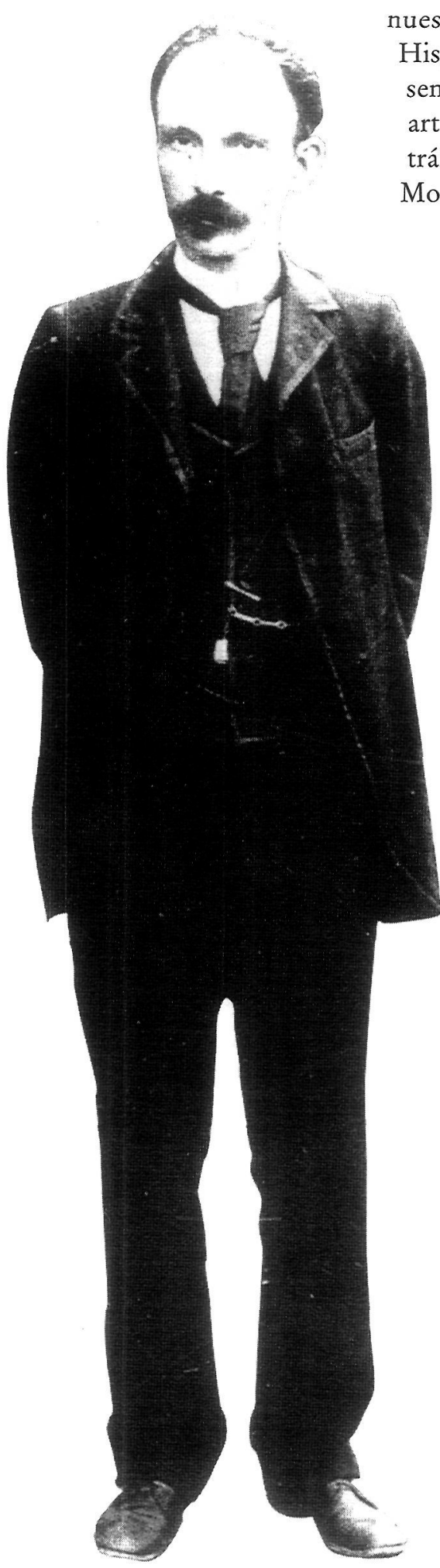

José Martí.

En la encrucijada del fin de siglo AMBROSIO FORNET nuestro Renacimiento: tuvo para Hispanoamérica - dijo- «el mismo sentido de crisis histórica, cultural y artística» que tuvo para Europa el tránsito de la Edad Media a la Edad Moderna. Permítanme introducir en esos juicios un matiz importante, $y$ es que en este caso se trataba de una modernidad «periférica» - para usar un término acuñado por Beatriz Sarlo-y sujeta, por tanto, a contradicciones profundas. $\mathrm{Me}$ interesa subrayar, además - ya que nos atañe directamente- que en esta época la tradicional antinomia civilización/barbarie fue siendo desplazada por la de cultura/civilización a medida que los emblemas del progreso material, los deslumbrantes signos del desarrollo técnico, aparecían contaminados de un salvajismo de nuevo cuño. Ahora la «civilización» no se contraponía a la barbarie únicamente, sino también a la cultura entendida como expresión de valores humanos y reducto de la memoria colectiva. (Por lo demás, este enfoque radical tenía profundas raíces en aquella modalidad del pensamiento latinoamericano cuyo eje era el sentido de la justicia. Baste recordar al chileno Francisco Bilbao: $\ll_{i} \mathrm{Oh}$, civilización, que se confunde con la moda hasta hacer que sea moda despreciar lo justo!» [El Evangelio americano, 1864]). El emblema visible de esa contradicción era el nuevo espacio urbano, la metrópolis moderna. En relación con ella encontramos, de un lado, la tajante afirmación de Casal, de clara estirpe bandeleriana: "Tengo el impuro amor de las ciudades, $/ y$ a ese sol que ilumina las edades/prefiero yo del gas las claridades». Y del otro, las desgarradoras protestas de Martí en Flores del destierro y en poemas como
«Amor de ciudad grande», de Versos libres: «Se ama de pie, en las calles, entre el polvo/de los salones y las plazas (...) ¿Qué es lo que falta/ que la ventura falta?». Permítanme una digresión: no ha de verse, en la confesión de Casal, una simple muestra de esnobismo hoy diríamos de mimetismo cultural-, sino la expresión sublimada de un conflicto profundo. Hoy sabemos que el esteticismo de los poetas era en parte una respuesta desafiante al mercantilismo de la burguesía, y en parte una dramática expresión de sus aspiraciones cosmopolitas. Como bien observa Octavio Paz, aludiendo al galicismo mental del primer Darío y sus epígonos: los modernistas no querían ser franceses, sino modernos, y no despreciaban a América, sino que aspiraban a situarla a la altura de París y de Londres. Martí vivió la experiencia de la modernidad en Nueva York, donde residió durante quince años, de 1880 a 1895, justamente la etapa en que la ciudad empezó a convertirse, desde el punto de vista del desarrollo urbano, en el epicentro del Nuevo Mundo. Pudo ver cómo se establecían allí la primera red telefónica y los elevadores eléctricos; cómo los carros tirados por caballos, que transitaban a una velocidad de seis millas por hora, cedían su lugar a los tranvías eléctricos que quintuplicaban esa velocidad y trasladaban el triple de pasajeros. Pudo ver cómo las avenidas y los bulevares se iluminaban, convirtiendo la noche en día y atrayendo al paseante - al flaneur de que habla Benjamin- hacia el espectáculo de las vidrieras y los placeres de la vida nocturna. Y pudo ver, sobre todo - en el corazón mismo de la ciudad y en los flamantes parques de diversiones- lo que medio siglo después $\mathrm{Ka}$ rel Reisman llamaría la «muchedumbre solitaria», esa otra cara de una "civilización» concebida casi exclusivamente en términos positivistas y pragmáticos. En su ensayo sobre Baudelaire, Benjamin cita una curiosa observación de Georg Simmel sobre el nuevo tipo de relaciones humanas que se establecen -o dejan de establecerse- en la gran ciudad: "Antes del desarrollo de los autobuses, de los trenes y de los tranvías en el siglo XIX - dice Simmel-, las gentes no se encontraron en la circunstancia de tener que mirarse mutuamente largos minutos, horas incluso, sin dirigirse la palabra unos a otros». 
En una crónica periodística sobre Coney Island, que hoy forma parte de sus Escenas norteamericanas, Martí describe como laberintos u hormigueros los recovecos de ese parque de diversiones neoyorkino donde se pierden las multitudes anónimas, ávidas de entretenimiento y novedad. (Por cierto, Julio Ramos considera esa crónica «una reflexión sobre el surgimiento de la cultura de masas», hecha desde la perspectiva crítica de un letrado). Martí volverá una y otra vez al tema en sus versos, sus crónicas y su célebre ensayo «Nuestra América» (1891). Ahora la ciudad no es vista como un fenómeno aislado sino como un centro hegemónico, que opera en detrimento de su periferia. En efecto, Martí se refiere a la «soberbia de las ciudades capitales», al odio o el desdén con que la ciudad mira al campo. Se trata de un enfrentamiento entre dos partes complementarias del organismo social, una de las cuales, sin embargo, envuelta en las banderas del Progreso, se niega a reconocer la legitimidad de la otra. En semejante situación, los países hispanoamericanos se ven forzados a imitar, o a la inversa, impedidos de crear, porque esto sólo es posible partiendo de las propias fuerzas, cuyo costado más autóctono, en este caso, se desestima. «Eramos una máscara - dice Martí, aludiendo a la imagen que de sí mismos proyectaban los sectores letrados de Hispanoamérica-, con los calzones de Inglaterra, el chaleco parisiense, el chaquetón de Norteamérica y la montera de España». Pero la realidad desautorizaba o burlaba una y otra vez esos refinados o grotescos simulacros: «[E]l libro importado ha sido vencido en América por el hombre natural. Los hombres naturales han vencido a los letrados artificiales. El mestizo autóctono ha vencido al criollo exótico. No hay batalla entre la civilización y la barbarie, sino entre la falsa erudición y la naturaleza». Diez años antes, aludiendo al pesimismo de salón que habían puesto de moda ciertos poetas franceses, Martí lo atribuía a una variante del mercantilismo muy propia de las ciudades opulentas, o para decirlo con sus propias palabras, a «literatos sin empleo en la ciudad sobrada de literatura». Conviene añadir esta visión iconoclasta de lo «moderno» - así como aquella doble concepción antropológica y democrática de la cultura - al acervo del pensamiento cubano de fines de siglo, para colocarlas junto a los elementos estéticos y políticos más conocidos del legado intelectual martiano: la renovación poética, el antiimperialismo, el anti-racismo, la concepción de una república «con todos y para el bien de todos».

\section{3}

Todo lo que pudiera yo agregar sobre el modernismo y el papel que en éste desempeñaron Martí y Casal, ha sido dicho de manera más precisa y aguda por diversos autores ${ }^{2}$. Como ejercicio crítico les propongo que hagan ustedes un análisis comparativo de tres poemas de temática semejante: «Salomé» (Nieve), de Casal, «La bailarina española» (Versos sencillos), de Martí, y «Elogio de la seguidilla» (Prosas profanas), de Darío. Es algo que nadie ha hecho todavía, hasta donde alcanzo a saber. No insinúo precedencias, diferencias ni similitudes porque en eso consiste el ejercicio, justamente: en que ustedes lo descubran por su propia cuenta.

El período de entreguerras (1878-1895) ha sido calificado por Vitier como «la etapa de mayor esplendor de la crítica cubana», una afirmación avalada por los nombres de Enrique José Varona, Enrique Piñeyro, Manuel Sanguily, Rafael María Merchán, Emilio Bobadilla (Fray Candil) y Manuel de la Cruz, para no citar a los novelistas y poetas que incursionaron ocasionalmente en la crítica. Imposible, en el escaso tiempo de que todavía disponemos, enumerar sus obras o intentar una valoración de sus aportes a nuestro movimiento intelectual, o más aún, detenernos en algunas particularidades de sus respectivas trayectorias, debidas en parte al campo cultural en que se movieron (Piñeyro radicaba en París, Merchán en Bogotá, Fray Candil en Madrid...). El género cuenta también con un anecdotario que incluye casos de desapariciones prematuras e iniciaciones precoces: el de Aurelio Mitjans, por ejemplo, autor de una imprescindible historia de la literatura cubana, que murió a los veintiseis años de edad; o el de José de Armas y Cárdenas (Justo de Lara), que a los dieciocho años se situó entre los primeros cervantistas de Hispanoamérica con la obra El Quijote de Avellaneda y sus críticos (1884). Ahora bien, la gran tarea de la intelectualidad cubana de la
2

Los estudiantes, disponen de dos excelentes compilaciones: José Marti: historia y literatura ante el fin del siglo XIX (Universidad de Alicante/Casa de las Américas, 1997) y Modernismo y modernidad en el ámbito hispánico (Universidad Internacional de Andalucía/Asociación Española de Estudios Literarios Hispanoamericanos, 1998), la primera editada por Carmen Alemany, Ramiro Muñoz y José Carlos Rovira, y la segunda por Trinidad Barrera. Puede consultarse también con provecho la compilación de Sonia Mattalía Modernidad y fin de siglo en Hispanoamérica. Alicante, Instituto de Cultura Juan Gil-Albert, 1996. 
época tenía un carácter eminentemente político: la formación de la conciencia nacional. Y serían los críticos separatistas - algunos de ellos, como Sanguily, destacados luchadores por la independencia - los que se mostrarían más aptos para llevar a cabo la empresa, sobre todo después de 1887 , cuando pudieron hacerlo dentro de los marcos legales. El Imaginario específico de la nación -como entidad histórica no sólo diferenciada de España sino enfrentada a ella- iba a ser construido a través de la memoria colectiva, la crítica al sistema colonial y la rivalidad o la alianza táctica con los autonomistas, que ofrecían tribunas respetables para la agitación política. Se trataba de un arduo proceso de descolonización ideológica que debía comenzar por el reconocimiento tanto de los valores propios como de la aptitud de los criollos mismos para el ejercicio del gobierno independiente. El nivel de autoestima en que se hallaban aquéllos en vísperas de la Guerra de los Diez Años puede calcularse por el comentario de un escritor costumbrista, Luis Victoriano Betancourt, para quien la tradicional afición de los cubanos a la danza revelaba su incapacidad para sumarse a la corriente del progreso: «El gas alumbra - decía-, el vapor ruge, la electricidad truena y nosotros bailamos». Una guerra prolongada, escenario de hazañas increíbles - en la que el propio Betancourt participó desde el principio- sirvió de base para la construcción de un sujeto nacional inspirado en los arquetipos de la épica. Fuera de Cuba, Martí fue uno de los primeros artífices de esa imagen. En Cuba lo fueron Sanguily y, sobre todo, Manuel de la Cruz, cuya obra Episodios de la Revolución cubana (1890), relatos basados en el testimonio oral de los excombatientes, sirvió para mostrar al lector ese aspecto hasta entonces ignorado de su historia y de su propia naturaleza.

Lo curioso es que la ideología política acabó determinando hasta las preferencias estéticas y metodológicas de los críticos independentistas. Estos - y permítanme repetir aquí, más o menos textualmente, lo que dije en otra ocasión- mostraron su partidismo mediante el sencillo expediente de negarse a pensar en español. En efecto, eligieron como mentores intelectuales a los teóricos franceses - Taine, Guyau, Bouget, Lemaître...- para poner en evidencia no sólo que rechazaban la posible tutela intelectual de España sino también que reivindicaban el derecho de juzgar el pensamiento español «a la francesa», como expresión de un escolasticismo démodé. Para ellos se trataba de una lucha entre la reacción y el progreso, o personalizando, entre el lúcido Taine - representante de «la crítica con fundamento científico», como decía Cruz-y el iracundo Menéndez Pelayo, en quien Sanguily veía encarnarse «ese espíritu español ardoroso, clerical, fanático». Cruz se atrevió a afirmar que el pensamiento cubano, de vieja filiación anglo-francesa - cartesiano, sensualista, spenceriano...- - se había emancipado totalmente de «la patria potestad del intelecto español». «La inteligencia española, atrofiada por la teología - comentaba-, no cuenta en las influencias generadoras de la inteligencia cubana». La tendencia produjo uno de sus ejemplos más notables en La sensibilidad en la poesía castellana (1898), de Nicolás Heredia, quien intentó demostrar que entre los poetas españoles la víscera que menos trabajaba, según sus propias palabras, era el corazón. «Desde Herrera hasta Quintana — decía, con una frialdad que a duras penas lograba ocultar su hispanofobia - se escucha el ruido armonioso de una lengua bien rimada, pero pocas veces se nota el latido de una emoción sentida con calor y expresada con verdad».

Quisiera proponerles otro ejercicio, para terminar, relacionado esta vez con las dos novelas más significativas del periodo, Mi Tío el empleado y Leonela. En la primera, un palurdo llamado Vicente Cuevas llega a Cuba sin un céntimo en el bolsillo y, gracias a diversos factores - todos relacionados con los distintos niveles de corrupción que prevalecen en el mundo colonial - acaba regresando un buen día a España con un título nobiliario, una fortuna personal y una bella y acaudalada criolla. En la segunda, el ingeniero John Valdespina -nacido en Cuba pero educado en los Estados Unidos- se establece en una zona rural de la Isla con el propósito de construir un ferrocarril por cuenta de la compañía minera Smithson Bros. Como parte de su misión, funda un pequeño pueblo, Smithson City, «algo nuevo, exótico, fuera del medio ambiente tropical», semejante a «uno de esos graciosos caseríos de las márgenes del Hudson» que podían verse en las cercanías de Nueva York. To- 
do es borrado de golpe por el torbellino de la guerra. Valdespina, además, es víctima de un equívoco trágico relacionado con la pasión que suscita en dos hermanas gemelas, idénticas entre sí. Mi pregunta es la siguiente: ¿no se tratará, en ambos casos, de variaciones sobre el tema civilización/barbarie, metáforas sobre la imposibilidad de la modernización en el mundo colonial o en sistemas donde sobrevi- van, más o menos encubiertas -para decirlo con palabras de hoy- las estructuras coloniales o neocoloniales, típicas del mundo subdesarrollado? ¿Tendrá el Primer Magistrado de El recurso del método algún parentesco remoto con Vicente Cuevas? ¿Será John Valdespina uno de los antepasados del Santos Luzardo de Doña Bárbara? 